\title{
Targeted therapy in advanced desmoid tumors: Current perspectives
}

Research Article

\author{
Amrallah A. Mohammed ${ }^{1 *}$,Hani EL-Tanni², Hani M. EL-Khatib ${ }^{3}$ \\ ${ }^{1}$ Department of Medical Oncology, Faculty of Medicine, Zagazig University, \\ Zagazig, Egypt \\ ${ }^{2}$ King Salman Armed Forces Hospital, Tabuk City \\ ${ }^{3}$ Oncology Center, King Abdullah Medical City-Holy Capital, Makkah
}

Received 21 November 2020; Accepted 11 December 2020

\begin{abstract}
Background: Desmoid tumors/aggressive fibromatosis (DTs/AF) are cytological bland fibrous neoplasms originating from the musculoaponeurotic structures throughout the body. The exact cause still remains unknown, however, they may present sporadically or as a manifestation of a hereditary syndrome called familial adenomatous polyposis (FAP). Although they lack the capacity to establish metastases, DTs/AF may be devastated and occasionally fatal. As a result of the heterogeneity of DTs/AF, treatment needs to be individualized to improve local tumor control and maintain patients' quality of life. Therefore, after a multidisciplinary approach, all treatment options should be discussed with patients. Where systemic chemotherapy has been shown to be unsuccessful with marked side effects in case of advanced DTs/AF, new therapeutic options are needed.

Methods: A Medline search was conducted and published articles in different studies from 2000 to the present were reviewed. Conclusion: More research is needed to illustrate both the prognostic and predictive factors of the targeted therapy and the value of their combinations with or without other treatment modalities to get the best result for the treatment of advanced DTs/AF.
\end{abstract}

Keywords: Desmoid tumors • aggressive fibromatosis • targeted therapy • molecular pathogenesis

\section{Introduction}

The Greek word "desmos", which means tendon or band like, has been the origin of the term desmoids and was coined by Muller in 1838. Desmoid tumors (DTs), also known as aggressive fibromatosis (AF), are benign fibrous growth that generally may occur to the root of the mesentery (intra-abdominal desmoids), in the abdominal wall (abdominal desmoids), and outside the abdomen, mainly in the shoulder or pelvic girdles (extra-abdominal desmoids). ${ }^{[1]}$

DTs are among the rarest of tumors, the estimated incidence of the general population is 2-4 people per million per year. They are rare in the extremes of age; individuals between the age of 15-60 years are the most commonly affected, slightly more common in women, without racial or ethnic predisposition. Although they don't exhibit the histological features to classify them as sarcomas, DTs are often considered as low- grade sarcoma because of the high tendency for local recurrence after excision. ${ }^{[2]}$

Soon it was not clear whether DTs should be considered a reactive proliferation or a malignant process. These were considered as just tumors; do we believe them as malignant or benign tumors? Based on patients' outcomes; deformity, morbidity, and mortality resulting from local destruction and potential obstruction of vital structures and organs requiring frequent hospitalization, some researchers would consider them as malignant diseases. However, due to lacking the main feature of malignancy; metastasis, others considered them as benign. ${ }^{[3]}$

DTs may infiltrate neighboring structures, stretching along the facial planes, and bones. Severe and even fatal complications are sometimes caused by these tumors, especially when these destroy vital organs. [4] Owing to their heterogeneity, tumors' behavior may range from spontaneously regressing or stable to rapidly 
progressive with a varying response to therapy. So, observation is the standard therapy.

To cover therapies designed to target the events that derive tumor initiation or progression, it is important to understanding the molecular pathogenesis. Targeted therapy had changed the natural history of many cancers especially breast, colon, and lung cancers. ${ }^{[5,6]}$ This section will discuss some aspects of the targeted therapies used in DTs/AF.

\section{Molecular Pathogenesis}

The molecular events that lead to DTs/AF formation are not completely understood. However, growing evidence suggests the involvement of the adenomatous polyposis coli $(A P C)$ gene in familial adenomatous polyposis $(F A P)$. In contrast, $A P C$ mutations are uncommon for sporadic desmoids, which usually arise from mutations in the gene for beta-catenin, CTNNB1 (7). Gardner syndrome is defined as FAP with extra-abdominal tumors (osteomas, DTs, and other tumors), and was considered as a separate disease until the identification of $A P C$ gene, at which point mutations were recognized as the underlying cause of both Gardener syndrome and FAP. Some authors consider Gardner syndrome as a subset of the FAP and have been proposed to replace the term Gardner syndrome by FAP. ${ }^{\left[{ }^{[]}\right.}$

\subsection{APC mutations in DTs}

A normal $A P C$ protein prevents the accumulation of beta-catenin, by mediating its phosphorylation and resultant degradation. In APC mutation, either germline or sporadic, premature truncation will lead to loss of the beta-catenin regulatory domain, therefore, betacatenin is accumulated and subsequently activates the transcription factor-4 (tcf-4), which in turn causes transcription of many genes such as $C Y C D 1$ and $M Y C$, leading to proliferation and enhanced survival..$^{\left[{ }^{[]}\right.}$

DTs have been reported to occur in $7.5 \%$ to $16 \%$ of patients with $F A P$, and the relative risk is much higher than the general population. Although they can occur with mutations in any $A P C$ gene location, in some reports, the occurrence of DTs/AF in patients with FAP may be correlated with the specific type and site of mutation. ${ }^{[10]}$ In one study of 36 patients from 20 families with FAP and mutations in codons 1445 to 1578 , all developed DTs. In a meta-analysis of many studies of FAP patients, the independent predictors of increased risk of DTs were a positive family history of DT, female sex, and an APC mutation 3 ' to codon 1399. ${ }^{[11]}$ A study done by Wallis et al. revealed that the highest risk of developing DTs (100\%) exists on the APC mutation in codons 13951493. ${ }^{[12]}$ Another study of 953 FAP patients from 187 families revealed that mutations between codons 1310 and 2011 were associated with a six-fold risk of DTs. [13] The relationship between genotype and phenotype suggests specific roles of the APC protein in different tissues. For example, dental manifestations of Gardener syndrome have been suggested to be associated with mutations at or near codon 1556. ${ }^{[14]}$

\subsection{Wnt/beta-catenin pathway in DTs}

The Wnt/beta-catenin signaling pathway is thought to play a major key in the molecular pathogenesis of DTs, both those associated with FAP and sporadic tumors. The basic features of the Wnt signaling pathway are illustrated in Figure 1. ${ }^{[15]}$

As discussed before, the levels of beta-catenin in the cell are regulated by phosphorylation, which results in the destruction of beta-catenin in the proteasome. Activation of the Wnt pathway was initiated by the binding of an external ligand causing inhibition of the kinase activity of the $A P C$ complex resulting in greater levels of beta-catenin in the cell. Mutations in the betacatenin gene have been found in sporadic DTs with variable prevalence (39 to $87 \%$ ).

In a retrospective study of patients with extraabdominal DTs, Domont and colleagues reported CTNNB1 mutations in $87 \%$ of patients, and the 5-year RFS rate was significantly worse in patients with CTNNB1 mutation, regardless of the genotype, compared with wild-type tumors (49\% vs. $75 \%$, respectively). ${ }^{[16]}$

Three distinct mutations, 41A, 45F, and 45P, were identified with $59 \%, 33 \%$, and $8 \%$ of cases, respectively. Mutation 45F was associated with a high risk of recurrence; 5 -year RFS rate was $23 \%$ for patients harboring $45 \mathrm{~F}$ mutation compared to $57 \%$ for those with $41 \mathrm{~A}$ and $68 \%$ for those with no mutations, after primary resection, ${ }^{[17]}$ which are matched with the study done by Columbo et al. ${ }^{[18]}$

In contrast to these findings, Mullen and colleagues reported that CTNNB1 mutation status was not associated with any statistically significant difference in recurrence risk in a subset of 115 patients with DTs who underwent macroscopically complete surgical resection. ${ }^{[19]}$ At a median follow-up of 31 months, the 5-year RFS rates were $58 \%$ and $74 \%$, for patients with CTNNB1 mutations and for those with wild-type tumors, respectively.

In fact, there is no agreement on the prognostic significance of different beta-catenin mutations. 


\section{A. Normal cell}

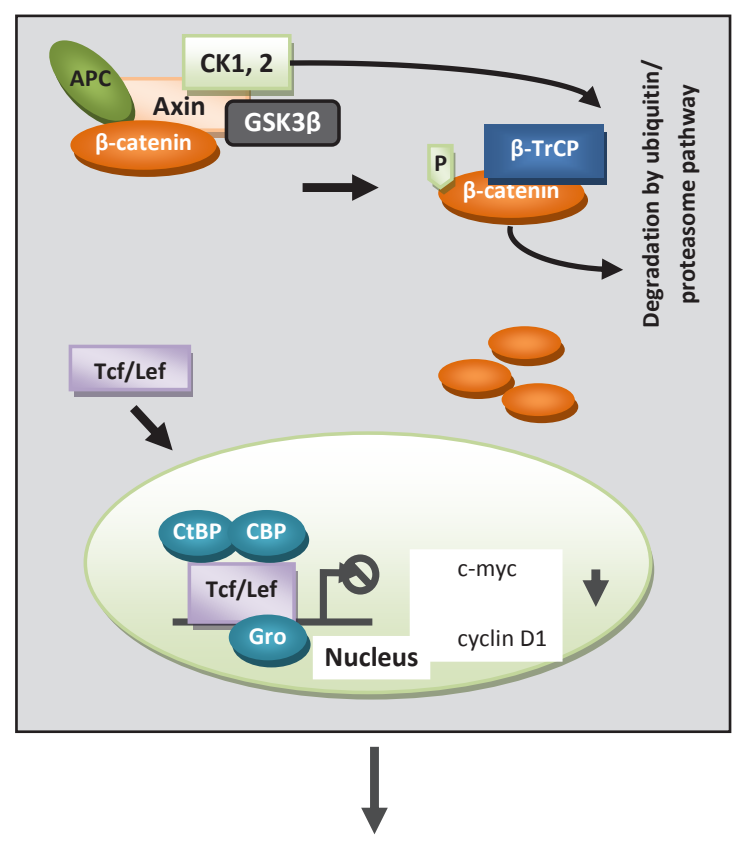

Controlled cell growth

B. Malignant cell

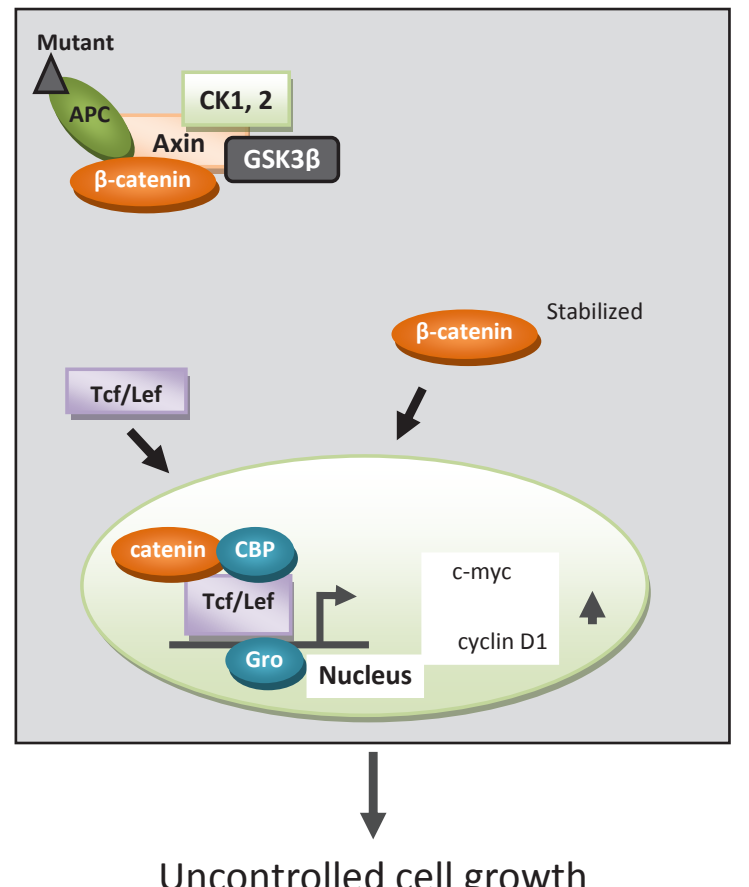

Figure 1: The Wnt-signaling pathway. (A) illustrates the down-regulation of $\beta$-catenin transactivation activity in normal epithelial cell. (B) shows the role of mutations in the APC or $\beta$-catenin protein in the regulation of $\beta$-catenin level and its transactivation property in malignant cell.
Additional prospective studies are needed to confirm whether genotyping of CTNNB1 may provide important information about the risk of recurrence and patients' selection for therapeutic options.

\subsection{Receptor tyrosine kinases and signal transduction}

Evidence anticipates that receptor tyrosine kinases (RTKs) such as platelet-derived growth factor receptor, $\alpha$ or $\beta$ type (PDGFR $\alpha$ or PDGFR $\beta$ ), epidermal growth factor receptor (EGFR), receptor tyrosine- protein kinase erbB-2 (HER-2), and mast/stem cell growth factor receptor (KIT) are active in DTs/AF. However, it failed to detect correlations between the expression or activation status of these RTKs and responses to receptor tyrosine kinases inhibitors (RTKI). ${ }^{[20,21]}$

\subsection{Chromosomal anomalies}

Many chromosomal abnormalities have been described in DTs/AF, especially the occurrence of loss of $6 q, 5 q$, trisomy 8,20 , and monosomy 20 . The presence of trisomy 8 and 20 occurs in $25-30 \%$ of tumors, and the proportion of cells affected in tumor samples had been reported to vary from $2 \%$ to $25 \%$. Till now, the clinical value of these genetic abnormalities is unclear, however, in some reports, their presence has been associated with a higher risk of local recurrence. ${ }^{[22]}$

\subsection{Others}

There is no consensus on the importance of $\mathrm{Ki}-67$ and p53 in DTs/AF; however, some reports have considered them markers for reduced disease-free survival. ${ }^{[23]}$

In trying to explain the lack of DTs/AF to metastasize, Bacac et al. revealed that lower expression of osteopontin secreted protein and nodular fasciitis, which might help in understanding their inability to metastasize. ${ }^{[24]}$

In the Wnt/beta-catenin pathway, the cyclooxygenase-2 gene is triggered; this gene's activity contributes to tumorigenesis by inhibiting apoptosis, stimulating angiogenesis and invasiveness, and modulating cell proliferation by increasing the expression of growth factors such as PDGFs. ${ }^{[25]}$ Many studies have proved that DTs/AF had a high estrogen level (ER), but negative for progesterone receptor (PR). This information suggests that they may grow under hormonal control and can possibly be influenced by hormonal manipulations. ${ }^{[26]}$ 


\section{Targeted Therapies}

Due to disease heterogeneity (ranged from spontaneous regression to rapidly progressive course), the observation was considered the standard therapy. Systemic treatment should be thought when local treatment of curative intent is not achievable. Depending on ER overexpression, hormone treatment is an accepted strategy in the first-line setting in the combination with non-steroidal anti-inflammatory drugs (NSAIDs). Cytotoxic chemotherapy is a valid alternative option after failure of hormonal therapy, NSAIDs or rapidly progressive, unresectable disease. In diseases such as DTs/AF, where the curative option is stingy, the main goal of treatment is to improve quality of life with relatively fewer side effects. Several targeted agents have been recently assessed. ${ }^{[27]}$

\subsection{Imatinib}

Imatinib mesylate is a small-molecule TKI that was initially developed as a 2-phenylaminopyrimidine derivative specific to PDGFR. It was subsequently found to be a potent inhibitor of ABL kinases and was also found to inhibit the RTK and KIT. Mace and colleagues revealed objective remissions and disease stabilization in two patients with unresectable and progressive DTs/ AF when treated by imatinib. ${ }^{[28]}$

In phase II clinical study, $84 \%$ of patients had mutations involving the Wnt pathway (APC or CTNNB1), imatinib was used in a dose $800 \mathrm{mg} /$ day to treat patients with advanced DTs/AF. The results revealed partial response (PR) and stable disease (SD) in $15.7 \%$ and $21 \%$ of patients, respectively. ${ }^{[29]}$ Similar observations have been reported by Chugh et al. ${ }^{[30]}$

Long term follow up results of phase II study done by the French Sarcoma Group also showed that at 3 months, $3 \%$ of patients achieved complete response (CR) and $9 \%$ $\mathrm{PR}$ in patients with recurrent or progressive DTs/AF. At a median follow up of 34 months, the non-progression rates at 3,6 , and 12 months were, respectively, $91 \%, 80 \%$, and $67 \%$. The 2-year progression-free survival (PFS) and overall survival (OS) rates were 55\% (95\% Cl 39-69) and $95 \%$ (95\% Cl 82-99), respectively. Imatinib toxicity was similar to that previously reported in the literature..$^{[31]}$

\subsection{Sorafenib}

Sorafenib (BAY-43-9006) is a multi-targeted oral TKI, inhibiting KIT, PDGFR, and VEGFR. In a retrospective cohort, Gounder et al reviewed the data for 26 patients with DTs treated with $400 \mathrm{mg}$ oral daily sorafenib with dose adjustment. The median dose was $200 \mathrm{mg} /$ day. Some patients required dose modifications to $200 \mathrm{mg}$ every other day, meanwhile others tolerated alternating doses of $400 \mathrm{mg}$ and $200 \mathrm{mg}$ daily (300 $\mathrm{mg} /$ day). Sorafenib was the first-line therapy in 11 patients and subsequent therapy in 15 patients after a median of 2 prior lines of therapy. The previous systemic treatment included hormonal manipulation, TKIs, and chemotherapy. $88.5 \%$ of patients had shown evidence of progressive disease, whereas $11.5 \%$ of patients had achieved maximum benefit. At a median of 6 months of treatment, $25 \%$ of patients exhibited $\mathrm{PR}, 70 \%$ with SD, and $5 \%$ with progression and death. There was a statistically significant radiological benefit in extremity DTs/DF rather than intra-abdominal tumors $(p=0.03) .^{[32]}$

\subsection{Sunitinib}

Sunitinib malate is a multi-targeted TKI with activity against VEGFR-1, VEGFR-2, VEGFR-3, PDGFR- $\alpha$, PDGFR- $\beta$, KIT, and FLT3. In a prospective multicenter phase II study that included 19 patients with advanced DTs/AF showed that the OS rate was $26.3 \%$. With a median follow-up time of 20.3 months, the 2-year rates of PFS and OS were $74.7 \%$ and $94.4 \%$, respectively. According to this result, sunitinib is considered as an option in advanced DTs/AF. A prospective multicenter phase II trial included 19 patients with DTs/AF to evaluate the safety and efficacy of sunitinib. The treatment plan consisted of 3 weeks on and one week off $(37.5 \mathrm{mg} /$ day sunitinib). The tumor RR was the primary endpoint based on RECIST 1.0. The results showed that the ORR was $26.3 \%(95 \% \mathrm{Cl}, 6.3-45.7)$ and the disease control rate was $68.4 \%(95 \% \mathrm{Cl}, 47.5-89.3)$. The 2-year rates of PFS and OS were $74.7 \%$ and $94.4 \%$, respectively. Grade 3 or 4 AEs reported in more than $5 \%$ of patients were neutropenia (33.3\%), hand-foot syndrome $(5.3 \%)$, and diarrhea $(5.3 \%)$. Of the 12 patients with mesenteric DTs/AF, only 3 patients developed surgical complications (bowel fistula $[n=1]$, bowel perforation $[n=1]$, mesenteric mass bleeding $[n=1])$. The authors concluded that sunitinib had a potential antitumor activity with an acceptable side effect. ${ }^{[33]}$

In a case study done by Scheer et al., addressed that the sunitinib achieved PR after multiple lines of systemic chemotherapy in young women with DTs/AF in breast cancer. ${ }^{[34]}$ Moreover, the same results were reported by Skubitz et al. in another case report study. ${ }^{[35]}$ 
Table 1: Clinical trials in advanced desmoids tumors/Aggressive fibromatosis (DTs/AF).

\begin{tabular}{|c|c|c|c|c|c|}
\hline NCT ID & Trial description & Intervention & $\begin{array}{c}\text { Trial } \\
\text { phase }\end{array}$ & $\begin{array}{c}\text { Last } \\
\text { updated }\end{array}$ & $\begin{array}{l}\text { Estimated Study } \\
\text { Completion Date }\end{array}$ \\
\hline NCT01981551 & $\begin{array}{l}\text { To determine the response rate of } \\
\text { PF-03084014 in patients with DT/AF } \\
\text { progressed after receiving at } \\
\text { least one line of standard treatment. }\end{array}$ & $\begin{array}{c}\text { PF-03084014; } \\
\text { small-molecule } \\
\text { Gamma- secretase } \\
\text { inhibitor }\end{array}$ & Phase 2 & $\begin{array}{l}\text { October 6, } \\
2015\end{array}$ & December 2016 \\
\hline NCT02495519 & $\begin{array}{l}\text { To define the activity of imatinib in the } \\
\text { treatment of DT/AF, progression after } \\
\text { local treatment and to determine the } \\
\text { molecular basis for response. }\end{array}$ & Imatinib & Phase 2 & July 10, 2015 & December 2016 \\
\hline NCT02066181 & $\begin{array}{l}\text { To compares the effects of sorafenib in } \\
\text { patients with previously treated DT/AF. }\end{array}$ & $\begin{array}{l}\text {-Sorafenib } \\
\text {-Laboratory Biomarker } \\
\text { Analysis } \\
\text { - Quality-of-Life } \\
\text { Assessment } \\
\text { - Placebo }\end{array}$ & Phase 3 & $\begin{array}{l}\text { December 22, } \\
2015\end{array}$ & March 2016 \\
\hline NCT01137916 & $\begin{array}{l}\text { To evaluate the activity and safety of } \\
\text { imatinib in patients with DTs/AF who, } \\
\text { after receiving the standard } \\
\text { therapy }\end{array}$ & Imatinib & Phase 2 & $\begin{array}{l}\text { December 1, } \\
2015\end{array}$ & June 2016 \\
\hline NCT01265030 & $\begin{array}{l}\text { To evaluate mTOR inhibitor, clinical and } \\
\text { histological studies following a course of } \\
\text { pre-operative Sirolimus. }\end{array}$ & Sirolimus & $\begin{array}{l}\text { Phase } 1 \\
\text { Phase } 2\end{array}$ & $\begin{array}{l}\text { Last updated: } \\
\text { September 22, } \\
2015\end{array}$ & March 2017 \\
\hline NCT01876082 & $\begin{array}{c}\text { To evaluate efficacy and safety of } \\
\text { pazopanib versus a chemotherapy } \\
\text { protocol combining methotrexate and } \\
\text { vinblastine in progressive } \\
\text { DTs. }\end{array}$ & $\begin{array}{l}\text { Drug: pazopanib } \\
\text { treatment } \\
\text { Drug: Active } \\
\text { Comparator: } \\
\text { Vinblastine and } \\
\text { Methotrexate }\end{array}$ & Phase 2 & $\begin{array}{l}\text { November 25, } \\
2015\end{array}$ & July 2019 \\
\hline NCT01273168 & $\begin{array}{l}\text { To test the safety and effectiveness } \\
\text { of daily endoxifen in individuals with } \\
\text { hormone receptor positive DTs after } \\
\text { first line. }\end{array}$ & Z-Endoxifen & Phase 1 & July 30, 2015 & October 2016 \\
\hline NCT02354560 & $\begin{array}{c}\text { To determine the lowest dose of } \\
\text { erythromycin that can inhibit growth of in } \\
\text { DT/AF. }\end{array}$ & Erythromycin & Phase 4 & $\begin{array}{l}\text { January } 29 \\
2015\end{array}$ & December 2017 \\
\hline NCT01608867 & $\begin{array}{l}\text { To determine the safety of } \\
\text { OMP-54F28 in subjects with previously } \\
\text { treated DT/AF. }\end{array}$ & OMP-54F28 & Phase 1 & $\begin{array}{l}\text { April 13, } \\
2015\end{array}$ & July 2016 \\
\hline
\end{tabular}

Information based on clinical trials listing on clinicaltrials.gov. NCT ID National Clinical Trials Identifier*Biomarkers include; Cadherin-associated protein, beta 1 (CTNNB1) genotype, platelet-derived growth factor receptor (PDGFR), vascular endothelial growth factor (VEGF).

\subsection{Pazopanib}

Pazopanib is a multi-tyrosine kinase inhibitor of VEGFR-1, VEGFR-2, VEGFR-3, (PDGFR)- $\alpha$, and KIT. It has been approved by the U.S. Food and Drug Administration (FDA) and by the European Medicines Agency (EMA) for the treatment of advanced renal cancer and soft-tissue sarcomas (STS).

In two different institutions, two patients with progressive DTs/AF were treated with pazopanib showed marked clinical improvement lasted for more than one year, with better and tolerable toxicity than conventional chemotherapy. ${ }^{[36]}$

A multicenter randomized non-comparative phase II study was conducted to evaluate the safety and efficacy of pazopanib compared to methotrexate/vinblastine (MV) in patients with DTs. The results showed that in the pazopanib arm, the PR was detected in $37 \%$ of patients and SD in $45.7 \%$. While in MV-arm, the PR in $25 \%$ and $\mathrm{SD}$ in $30 \%$. The 6-month non-PD rate was $86 \%(95 \%$ $\mathrm{Cl}=72.1-94.7)$ in pazopanib arm and $50 \%(95 \% \mathrm{Cl}=$ 27.2-72.8) in MV-arm. ${ }^{[37]}$

\subsection{Secretase Inhibitor}

B-secretase is a membrane-anchored aspartyl protease in the pepsin family, while $y$-secretase is an unusual protease with highly promiscuous through the transmembrane domain of its substrates. PF03084014 is a $y$-secretase inhibitor evaluated in patients with refractory, recurrent, progressive DTs/ AF. A prospective study evaluated PF-03084014 on 17 patients with recurrent or refractory DTs/AF. The 
treatment plan consisted of PF-03084014 $150 \mathrm{mg}$ orally twice a day in 3-week cycles. the evaluation was at cycle one and every 6 cycles. The primary endpoint was objective RR. The mutations either germline or somatic in APC and CTNNB1 were genotyped in blood samples and archival tumor. The results revealed that $88 \%$ of patients had mutations in CTNNB1 or APC genes. 29 $\%$ had PR, and another $29 \%$ experienced SD. Patients reported that the drug is tolerable. In conclusion, the investigators reported that PF-03084014 had a promising clinical activity with a tolerable side effect. ${ }^{[38]}$

\section{Conclusion}

The lack of effective therapeutic options and its serious complications make DTs/AF a challenging disease. Although DTs/AF is not strictly considered a malignancy, the mechanisms that lead to a local invasion, tissue destructions and survival are similar to those in cancer.

\section{References}

[1] Biermann JS: Desmoid tumors. Curr Treat Options Oncol 2000; 1:262-266.

[2] Dufresne A, Paturel M, Alberti L, et al. Prediction of desmoid tumor progression using miRNA expression profiling. Cancer Sci 2015; 106: 650655.

[3] Wu C, Amini-Nik S, Nadesan P, et al. Aggressive fibromatosis (desmoid tumor) is derived from mesenchymal progenitor cells. Cancer Res. 2010; 70: 7690-8

[4] Dalen BP, Bergh PM, Gunterberg BU. Desmoid tumors: a clinical review of 30 patients with more than 20 years' follow-up. Acta Orthop. Scand. 2003, 74, 455-459.

[5] Malik F, Korkaya H, Clouthier SG, et al. Breast cancer heterogeneity: need to review current treatment strategies. Curr Breast Cancer Rep 2012; 4: 225-31.

[6] Rothschild SI, Gautschi O. Src tyrosine kinase inhibitors in the treatment of lung cancer: rationale and clinical data. Clinical Investigation 2012; 2: 387-96.

[7] Escobar C, Munker R, Thomas JO, et al. Update on desmoid tumors. Ann Oncol 2012; 23: 562.

[8] Schiessling S, Kihm M, Ganschow P, et al. Desmoid tumour biology in patients with familial adenomatous polyposis coli. Br J Surg 2013; 100 : 694-703.
The treatment of DTs/FA is a multidisciplinary decision on qualified center familiar with this disease. Observation is the standard of care, starting the treatment will depend on various factors including clinical presentation, expected side effect or complication of therapy, and performance status. If the decision is to treat, the data on pazopanib is promising. The clinical trials should be incorporated into the management.

We hoped that the illustration of the main role of beta-catenin and APC in the pathogenesis of DTs/AF will lead to developing promising molecular therapeutic targets. We summarized the most important clinical trials in advanced DTs/AF in Table 1.

\section{Conflict of interest}

The authors certified that there is no actual or potential conflict of interest in relation to this article.

[9] Lazar AJ, Hajibashi S, Lev D. Desmoid tumor: from surgical extirpation to molecular dissection. Curr Opin Oncol 2009; 21: 352.

[10] Nieuwenhuis $\mathrm{MH}$, Vasen HF. Correlations between mutation site in APC and phenotype of familial adenomatous polyposis (FAP): a review of the literature. Crit Rev Oncol Hematol 2007; 61: 153.

[11] Sinha A, Tekkis PP, Gibbons DC, et al. Risk factors predicting desmoids occurrence in patients with familial adenomatous polyposis: a meta-analysis. Colorectal Dis 2011; 13: 1222-9.

[12] Wallis YL, Morton DG, Mc Keown CM, et al. Molecular analysis of the APC gene in 205 families: extended genotype-phenotype correlations in FAP and evidence for the role of APC amino acid changes in colorectal cancer predisposition. J Med Genet 1999; 36: 14-20.

[13] Bertario L, Russo A, Sala P, et al. Multiple approach to the exploration of genotype-phenotype correlations in familial adenomatous polyposis. J Clin Oncol 2003; 21: 1698.

[14] Church J, Xhaja X, LaGuardia L, et al. Desmoids and genotype in familial adenomatous polyposis. Dis Colon Rectum. 2015; 58: 444-8.

[15] Narayan S and Roy D. Role of APC and DNA mismatch repair genes in the development of colorectal cancers. Mol Cancer. 2003; 2: 41. 
[16] Dômont J, Salas S, Lacroix L, et al. High frequency of beta-catenin heterozygous mutations in extraabdominal fibromatosis: a potential molecular tool for disease management. $\mathrm{Br} \mathrm{J}$ Cancer 2010; 102: 1032-1036.

[17] Lazar AJ, Tuvin D, Hajibashi S, et al. Specific mutations in the beta-catenin gene (CTNNB1) correlate with local recurrence in sporadic desmoids tumors. Am J Pathol 2008; 173: 1518-1527.

[18] Colombo C, Miceli R, Lazar AJ, Perrone F, et al. CTNNB1 45F mutation is a molecular prognosticator of increased postoperative primary desmoids tumor recurrence: An independent, multicenter validation study. Cancer 2013; 119: 3696-3702.

[19] Mullen JT, DeLaney TF, Rosenberg AE, et al. betacatenin mutation status and outcomes in sporadic desmoids tumors. Oncologist 2013; 18: 10431049.

[20] Cho NL, Carothers AM, Rizvi $H$, et al. Immunohistochemical and molecular analysis of tyrosine kinase activity in desmoid tumors. J Surg Res. 2012; 173: 320-6.

[21] Santos GA, Cunha IW, Rocha RM, et al. Evaluation of estrogen receptor alpha, estrogen receptor beta, progesterone receptor, and CKIT expression in desmoids tumors and their role in determining treatment options. Biosci Trends. 2010; 4: 25-30.

[22] Salas S, Chibon F, Noguchi T, et al. Molecular characterization by array comparative genomic hybridization and DNA sequencing of 194 desmoid tumors. Genes Chromosomes Cancer 2010; 49: 560-568.

[23] Gebert C, Hardes J, Kersting C, et al. Expression of beta-catenin and p53 are prognostic factors in deep aggressive fibromatosis. Histopathology 2007; 50: 491-497.

[24] Bacac M, Migliavacca E, Stehle JC, et al. A gene expression signature that distinguishes desmoid tumours from nodular fasciitis. J Pathol. 2006; 208 543-53.

[25] Urakawa $\mathrm{H}$, Nishida $\mathrm{Y}$, Naruse $\mathrm{T}$, et al. Cyclooxygenase-2 overexpression predicts poor survival in patients with high-grade extremity osteosarcoma: A pilot study. Clin Orthop Relat Res 2009: 467: 2932-2938.

[26] Hong H, Nadesan P, Poon R, et al. Testosterone regulates cell proliferation in aggressive fibromatosis (desmoid tumor). Br J Cancer 2011; 104: 1452-1458.

[27] de Camargo VP, Keohan ML, D'Adamo DR, et al. Clinical outcomes of systemic therapy for patients with deep fibromatosis (desmoid tumor). Cancer. 2010; 116: 2258-2265.

[28] Mace J, Sybil Biermann J, Sondak V, et al., "Response of extraabdominal desmoid tumors to therapy with imatinib mesylate," Cancer 2002; 95: 2373-2379.

[29] Heinrich MC, McArthur GA, Demetri GD, et al. Clinical and molecular studies of the effect of imatinib on advanced aggressive fibromatosis (desmoid tumor). J Clin Oncol 2006; 24: 11951203.

[30] Chugh R, Wathen JK, Patel SR, et al. Sarcoma Alliance for Research through Collaboration (SARC). Efficacy of imatinib in aggressive fibromatosis: results of a phase II multicenter Sarcoma Alliance for Research through Collaboration (SARC) trial. Clin Cancer Res 2010; 16: 4884-4891.

[31] Penel N, Le Cesne A, Bui BN, et al. Imatinib for progressive and recurrent aggressive fibromatosis (desmoid tumors): an FNCLCC/French Sarcoma Group phase II trial with a long-term follow-up. Ann Oncol 2011, 22: 452-457.

[32] Gounder MM, Lefkowitz RA, Keohan ML, et al. Activity of sorafenib against desmoids tumor/deep fibromatosis. Clin Cancer Res 2011; 17: 40824090.

[33] Jo JC, Hong YS, Kim KP, et al. A prospective multicenter phase II study of sunitinib in patients with advanced aggressive fibromatosis. Invest New Drugs. 2014; 32: 369-76.

[34] Scheer L, Lodi M, Molière S, Kurtz JE, Mathelin C.Medical treatment of mammary desmoidtype fibromatosis: which benefit? World J Surg Oncol. 2017: 18; 15: 86.

[35] Skubitz KM, Manivel JC, Clohisy DR, Frolich JW.Response of imatinib-resistant extra-abdominal aggressive fibromatosis to sunitinib: case report and review of the literature on response to tyrosine kinase inhibitors. Cancer Chemother Pharmacol. 2009; 64: 635-40.

[36] Martin-Liberal J, Benson C, McCarty $H$, et al. Pazopanib is an active treatment in desmoid tumour/aggressive fibromatosis. Clin Sarcoma Res. 2013; 26; 31: 13.

[37] Toulmonde M, Bellera C, Mathoulin-Pelissier $S$, et al.DESMOPAZ pazopanib (PZ) versus IV methotrexate/vinblastine (MV) in adult patients with progressive desmoid tumors (DT) a randomized phase II study from the French Sarcoma Group. ournal of Clinical Oncology 2018; 36: $11501-$ 11501. 
[38] Kummar S, O'Sullivan Coyne G, Do KT, et al. Clinical Activity of the $Y$-Secretase Inhibitor PF-03084014 in Adults with Desmoid Tumors (Aggressive Fibromatosis). J Clin Oncol. 2017 10; 35: 1561-1569. 